\title{
n-3 polyunsaturated fatty acids provoke a specific transcriptional profile in rabbit adipose-derived stem cells in vitro
}

\author{
Eкаterina Vackova $^{1}$ | Darko Bosnakovski ${ }^{2}$ | Bodil Bjørndal ${ }^{3}$ | Penka Yonkova ${ }^{4}$ | \\ Natalia Grigorova $^{1}$ | Zhenya Ivanova ${ }^{1}$ | Georgi Penchev ${ }^{4}$ | Galina Simeonova ${ }^{5}$ | \\ Lyuba Miteva $^{6}$ | Anelya Milanova ${ }^{1}$ | Tatyana Vachkova ${ }^{7}$ | Spaska Stanilova ${ }^{6}$ | \\ Ivan Penchev Georgiev ${ }^{1}$
}

${ }^{1}$ Department of Pharmacology, Animal Physiology and Physiological Chemistry, Faculty of Veterinary Medicine, Trakia University, Stara Zagora, Bulgaria

${ }^{2}$ Faculty of Medical Sciences, University Goce Delčev- Štip, Shtip, Macedonia

${ }^{3}$ Department of Clinical Science, University of Bergen, Bergen, Norway

${ }^{4}$ Department of Veterinary Anatomy, Histology and Embryology, Faculty of Veterinary Medicine, Trakia University, Stara Zagora, Bulgaria

${ }^{5}$ Department of Veterinary Surgery, Faculty of Veterinary Medicine, Trakia University, Stara Zagora, Bulgaria

${ }^{6}$ Department of Molecular Biology, Immunology and Genetics, Faculty of Medicine, Trakia University, Stara Zagora, Bulgaria

${ }^{7}$ Department of Chemistry and Biochemistry, Faculty of Medicine, Trakia University, Stara Zagora, Bulgaria

\section{Correspondence}

Ekaterina Vachkova, Animal Physiology Unit, Department of Pharmacology, Animal Physiology and Physiological Chemistry, Faculty of Veterinary Medicine, Trakia University, Stara Zagora, Bulgaria.

Email: katvach@gbg.bg

Funding information

Trakia University-FVM, Grant/Award

Number: Project 4/13

\begin{abstract}
Adipose-derived stem cells (ADSCs) possess multipotent properties, and their proper functionality is essential for further development of metabolic disorders. In the current study, we explored the impact of two n-3 LC-PUFAs (long-chain polyunsaturated fatty acids, DHA-docosahexaenoic; C22:6, and EPA-eicosapentaenoic; C20:5) on a specific profile of lipolytic-related gene expressions in the in vitro-differentiated subcutaneous and visceral ADSCs from rabbits. The subcutaneous and visceral ADSCs were obtained from 28-day-old New Zealand rabbits. The primary cells were cultured up to passage 4 and were induced for adipogenic differentiation. Thereafter, the differentiated cells were treated with $100 \mu$ g EPA or DHA for $48 \mathrm{hr}$. The total mRNA was isolated and target genes expression evaluated by real-time RCR. The results demonstrated that treatment of rabbit ADSCs with n-3 PUFAs significantly enhanced mRNA expression of Perilipin A, while the upregulation of leptin and Rab18 genes was seen mainly in ADSCs from visceral adipose tissue. Moreover, the EPA significantly enhanced PEDF (Pigment Derived Epithelium Factor) mRNA expression only in visceral cells. Collectively, the results suggest activation of an additional lipolysis pathway most evident in visceral cells. The data obtained in our study indicate that in vitro EPA up-regulates the mRNA expression of the studied lipolysis-associated genes stronger than DHA mainly in visceral rabbit ADSCs.
\end{abstract}

KEYWORDS

adipose tissue, docosahexaenoic, eicosapentaenoic, obesity, stem cells 


\section{1 | INTRODUCTION}

Previously, adipose tissue was considered an inert energy depot, but it is now known that this tissue is a unique endocrine organ (Kershaw \& Flier, 2004; Slavov \& Dzhelebov, 2010). It regulates energy homoeostasis (Choe, Huh, Hwang, Kim, \& Kim, 2016) and significantly affects the metabolic processes in the entire organism through secretion of different adipokines (Trayhurn \& Beattie, 2001; Wozniak, Gee, Wachtel, \& Frezza, 2009).

Disturbances in adipose tissue function are associated with development of visceral obesity, metabolic syndrome (MS), insulin resistance, hypertension, dyslipidemia, cardiovascular diseases etc. (Laclaustra, Corella, \& Ordovas, 2007; Georgiev et al., 2011) in humans and animals. These metabolic disorders occur due to changes in energy status and imbalance of regulatory molecules. The increased energy intake leads to obesity, which is manifested not only by an increase in the body fat depots, but also by remodelling of adipose tissue (Choe, Huh, Hwang, Kim, \& Kim, 2016). There are many changes both in the number and size of adipocytes, but the most important is the altered function of stem cells in adipose tissue, which aims to maintain the energy balance in the body (Choe et al., 2016; Penchev et al., 2017). The functional plasticity of those cells is essential for further development of metabolic disorders, due to their involvement in adipogenesis and in production of adipose-derived cytokines, hormones and metabolites. In this sense, the stem cells in adipose tissue appear as an appropriate target for therapy and reveal possibilities for manipulating cell response in prevention of related disorders using exogenous factors.

The process of differentiation of preadipocytes into mature adipocytes is manifested by the formation of lipid droplets in cell cytoplasm. This transition is initiated and regulated by some adipogenic transcription factors, such as peroxisome proliferator-activated receptor $\gamma$ (PPAR $\gamma$ ) (Schoonjans, Staels, \& Auwerx, 1996). The subsequent maintenance of fat droplets in the mature adipocytes is a result of the balance between the reactions supplying free fatty acids (FFA) for triacylglycerol (TAG) synthesis in adipose cells (lipoprotein lipase-LPL, catalysing the TAG hydrolysis in lipoproteins) and enzymes involved in lipolysis (breaking down of TAG in cells). The most important enzymes catalysing the latter process are adipose triglyceride lipase (ATGL, known as desnutrin), encoded by Pnpla2gene, and hormone-sensitive lipase (HSL), encoded by Lipe gene (Zimmermann et al., 2004; Ahmadian, Wang, \& Sul, 2010). The activity of these lipolytic enzymes, responsible for decreasing the levels of TAGs in the cells, is subordinated with a protein in the fat droplets shell-Perilipin A (a lipid droplet scaffold protein) (Brasaemle et al., 2000). Perilipin A is regulated by PPAR $\gamma$ on a transcriptional level, indicating the importance of this mechanism in the processes of formation and growth of the fat droplets in adipocytes (Arimura, Horiba, Imagawa, Shimizu, \& Sato, 2004).

In terms of dietetics, the quality of dietary fat and the content of long-chain polyunsaturated fatty acids (LC-PUFAs), particularly omega-3 ( $\omega-3$ or $n-3$ ), is of great importance. Among the n-3 PUFAs, docosahexaenoic (DHA; C22:6) and eicosapentaenoic (EPA; C20:5) acids are shown to decrease lipogenesis and to stimulate lipolysis (Todorčević \& Hodson, 2016), but the molecular mechanisms of these molecules on transcriptional regulation remain unclear. EPA is known to be an agonist and regulator of the PPAR gene expression (Chambrier et al., 2002), while DHA was proven to increase mitochondrial biogenesis through PPAR $\gamma$ upregulation in human adipose-derived stem cells (hADSCs) from subcutaneous fat depots (Chen et al., 2015).

Having in mind that all aforementioned factors are key regulators and/or modulators of lipolysis, in this study we designed a panel of lipolysis-related genes which include 8 genes and examined the changes of their expression after incubation of ADSCs with two n-3 LC-PUFAs (DHA and EPA). The obtained correlations would clarify whether the cell exposure to PUFAs has an agonistic or antagonistic effect on the PPAR $\gamma$-regulated metabolic pathways in lipid metabolism. While rabbits are considered as appropriate animal models for studying some obesity-related disorders (Aguilera, Ramirez-Tortosa, Mesa, RamirezTortosa, \& Gil, 2002; Yanni, 2004), the current study provides useful information for $\mathrm{n}$-3-PUFAs dependent specific gene expression profile, implemented for MS prevention in humans and animals.

\section{2 | MATERIAL AND METHODS}

\subsection{Animals and cell isolation procedure}

The cells were obtained from three 28-day-old New Zealand rabbits. The animals were euthanized in accordance with the recommendations and approval of the Local Committee for Humane Treatment of Animals. Isolation procedure was carried out as described by Vachkova et al. (2016). Briefly, the samples, weighing 1-1.5 g each, were collected from the subcutaneous (interscapular region) and visceral (perirenal region) fat depots, minced into fine pieces and digested with collagenase. Followed centrifugation at $300 \mathrm{~g}$ for $10 \mathrm{~min}$, the pellet was re-suspended, seeded into T25 tissue flasks in DMEM (Dulbecco's Modified Eagle's Medium), 10\% FBS (Foetal Bovine Serum) and antibiotic mixed solution (pen/strep/amphoB) all from Sigma (St. Louis, MO, USA) and incubated under humidified 5\% $\mathrm{CO}_{2}$ conditions at $37.5^{\circ} \mathrm{C}$ until reaching confluence. The achieved cells were cultured up to passage 4 and were used for the experiment. The experiment was duplicated.

\subsection{Adipogenic differentiation and experimental design}

The harvested subcutaneous and visceral ADSCs were seeded at $5 \times 10^{4} / \mathrm{ml}$ density, cultured in 12 -well plates with basal medium for 3 days until the monolayer became confluent. After that period, the cells were kept for an additional $24 \mathrm{hr}$ for growth arrest and treated with DMEM (high glucose), 10\% FBS, 0.1 mM 3-Isobutyl-1-methylxanthine (IBMX), $0.05 \mathrm{mM}$ indomethacin, $1 \mu \mathrm{M}$ dexamethasone, $10 \mu \mathrm{g} / \mathrm{ml}$ insulin and antibiotic mixed solution (pen/strep/amphoB), 
all from Sigma (St. Louis, MO, USA), for 3 days. On the third day, the medium was replaced with DMEM (high glucose), 10\% FBS, $10 \mu \mathrm{g} /$ $\mathrm{ml}$ insulin and antibiotic mixed solution (pen/strep/amphoB) for an additional three days. In total, this inducing/maintenance medium cycle was performed three times in order to fulfil the adipose differentiation programme (Bosnakovski et al., 2005).

At this stage, the experimental groups were formed as follows: control group, treated with DMEM; 10\% FBS, antibiotic mixed solution (pen/strep/amphoB); EPA-group, treated with control medium $+100 \mu \mathrm{g}$ EPA and DHA-group, treated with control medium $+100 \mu \mathrm{g}$ DHA. All groups were treated for $48 \mathrm{hr}$. In the current study, we used DHA (with purity $298 \%$ ) and EPA (with purity $\geq 99 \%$ ). Stock solutions were prepared by solving the PUFAs in sterile, cell culture-tested ethanol (all from Sigma-Aldrich) and aliquots were kept in dark conditions at $-20^{\circ} \mathrm{C}$. For the experimental treatment, each PUFA additionally diluted ex tempore in control medium up to final concentration of $100 \mu \mathrm{g} / \mathrm{ml}$ while ethanol reached final dilution of 1,000 -fold.

\section{3 | Other methods, related to multipotency verification}

In addition to the main experiment, the cells from both visceral and subcutaneous types were seeded in 24-well plates with average density $5 \times 10^{4} / \mathrm{ml}$ and cultivated in basal medium, under humidified $5 \% \mathrm{CO}_{2}$ conditions at $37.5^{\circ} \mathrm{C}$ until reaching confluence. The subsequent differentiation and staining procedures were performed, and the results were documented by microscopy as follow:

\subsection{1 | Adipogenic differentiation and Oil Red O staining}

After finishing the triplicated cycle of induction/maintenance medium treatment, the cells were washed with PBS and fixed with $10 \%$ ( $\mathrm{vol} / \mathrm{vol}$ ) neutral buffered formalin for $30 \mathrm{~min}$ at room temperature. A freshly prepared working solution of Oil Red O (Sigma, St. Louis,

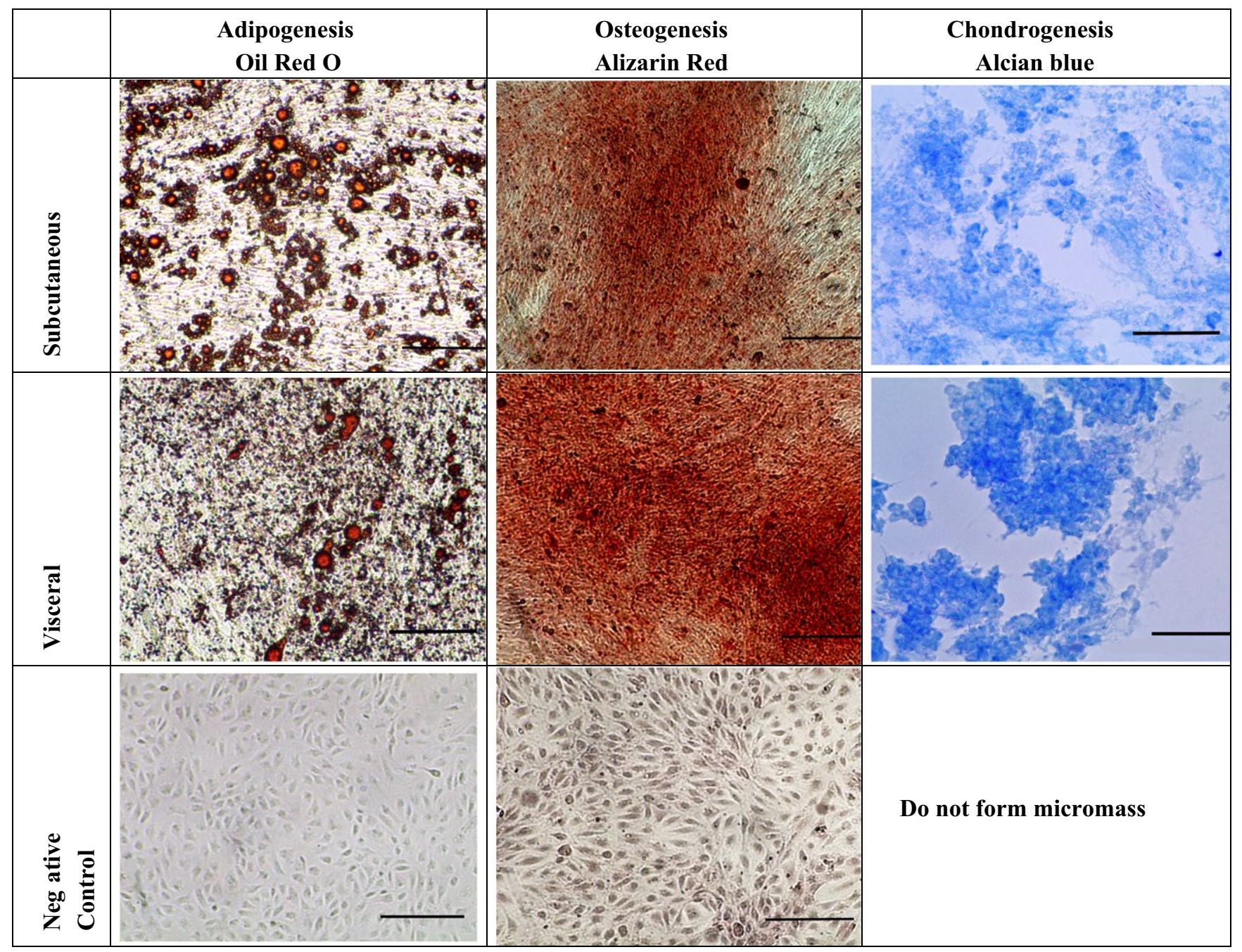

FIGURE 1 Functional multipotency of subcutaneous and visceral ADSCs: the samples and their negative controls stained with Oil Red $O$ for adipogenesis $(B a r=200 \mu \mathrm{m}$ ); the samples stained with Alizarin Red for osteogenesis (Bar $=350 \mu \mathrm{m}$ ) and their negative controls $($ Bar $=200 \mu \mathrm{m})$; the samples for chondrogenesis stained with Alcian blue (Bar $=50 \mu \mathrm{m})$ [Colour figure can be viewed at wileyonlinelibrary.com] 
MO, USA) was applied, and cells were incubated for $30 \mathrm{~min}$ at a room temperature. Subsequently, the stain was removed and the wells were washed with distilled water.

\subsection{2 | Osteogenic differentiation}

After the initial expansion, the cells were kept an additional $24 \mathrm{hr}$ for growth arrest and treated with osteogenic differentiation medium, containing DMEM; 10\% FBS, $0.1 \mu \mathrm{M}$ dexamethasone; $10 \mathrm{mM}$ $\beta$-glycerolphosphate; $50 \mu \mathrm{M}$ L-ascorbic acid and antibiotic mixed solution (pen/strep/amphoB), all from Sigma (St. Louis, MO, USA), for a period of 21 days. The medium was changed every three days. Alizarin Red S staining with $\mathrm{pH} 4.2$ visualized the extracellular calcium deposits in ADSCs in bright orange red, indicating early stages of bone formation.

\subsection{3 | Chondrogenic differentiation}

The chondrogenesis was performed in "pellet" culture system (Bosnakovski et al., 2004) by centrifugation of cells at a density of $2 \times 10^{5} / \mathrm{ml}$ at $400 \mathrm{~g}$ for $10 \mathrm{~min}$. The cells were treated with serumfree basal medium, supplemented with $10 \mathrm{ng} / \mathrm{ml}$ TGF $\beta-1$ (R\&D Systems, Inc.; Minneapolis, MN USA), $0.1 \mu \mathrm{M}$ dexamethasone and $50 \mu \mathrm{M}$ L-ascorbic acid. The medium was changed every third day for a 21-day period. The cells were stained in Alcian blue and treated with $0.1 \mathrm{M} \mathrm{HCl}$, for $5 \mathrm{~min}$ for detection of extracellular cartilagespecific proteoglycans. Samples embedded in gelatin and cryostat sections with thickness $6 \mu \mathrm{m}$ were obtained.

\section{Negative controls (NC)}

Fibroblasts obtained from rabbit kidney were used as negative controls during adipogenic, osteogenic and chondrogenic differentiation.

The images (Figure 1) were taken, using an inverted Telaval Carl Ziess JENA (Germany) microscope equipped with a MDCE-5 highresolution ocular camera (China).

\section{4 | Gene expression analysis}

The total RNA was isolated and purified using RNeasy Lipid Tissue Kit from Qiagen (Hilden, Germany) according to the manufacturer's protocol. The quality and quantity of total RNA was determined by ultraviolet absorbance at 260 and $280 \mathrm{~nm}$ with GeneQuant 1300 Spectrophotometer (GE Healthcare Bio-Sciences AB, Sweden).

Total RNA was used for first-strand cDNA synthesis by the RevertAid First Strand cDNA Synthesis Kit (Fermentas Life Science, Thermo Fisher Scientific ${ }^{\mathrm{TM}}$ ) according to the manufacturer's instructions. Reverse transcription was performed on a Quanta Biotech QB-96 (Quanta Biotech Ltd., Surrey, United Kingdom). The cDNA was stored at $-20^{\circ} \mathrm{C}$.

The $\mathrm{ABI}$ Prism $7900 \mathrm{H}$ sequence detection system (Applied Biosystems, Foster City, CA) was used for the real-time PCR reaction. It was run in 384-well Multiply PCR plates (Sarstedt Inc., Newton, USA), using SYBR Select Master Mix from Applied Biosystems and

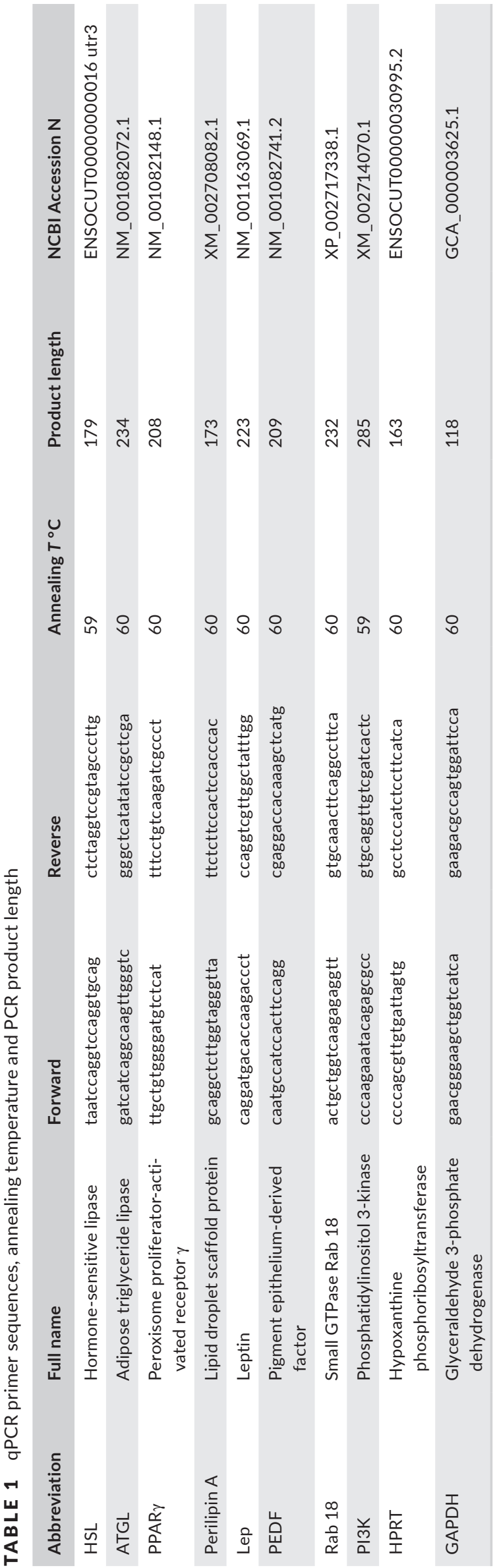


gene-specific primers from Sigma-Aldrich (Table 1). The primers for target and housekeeping genes (Table 1) were designed using published data in NCBI (www.ncbi.nlm.nih.gov) and Ensembl (www. ensambl.org). The product length and annealing temperatures were determined by web-based software Primer 3 (http://bioinfo.ut.ee/ primer3/). Standard curves were created basing on serial dilutions of pooled cDNA. The NormFinder software (http://moma.dk/normfinder-software) was used for estimation the best reference gene/ combination of genes. The best stability value (0.161) was obtained for the combination of Hypoxanthine phosphoribosyl transferase (HPRT) and Glyceraldehyde 3-phosphate dehydrogenase (GAPDH) genes. The ADSC mRNA was normalized to the arithmetic mean of HPRT and GAPDH, which were used as housekeeping genes, and subsequent statistical analysis was performed.

\section{5 | Statistical analysis}

All statistical analyses were performed with the raw data after normalization to the housekeeping genes, applying Statistica v.10 (StatSoft Inc., 1984-2011). The Mann-Whitney U test was carried out for estimation of the differences in expression of target genes between two independent groups. The results were presented by relative quantification of the target genes' change of expression from their relative controls. An additional Spearman's rank order test was used for determination of the correlation coefficients $(r)$ within parameters in each group. The network analysis Miru Evaluation v1.4 software (CKajeka, 2014-2016; https://kajeka.com) was used for visualization of the established correlations. For all tests, $p<0.05$ was considered significant.

\section{3 | RESULTS}

In order to express the functional multipotent properties of isolated subcutaneous and visceral ADSCs, protocols for adipogenic, osteogenic and chondrogenic differentiation were applied and the results were presented in Figure 1.

After exposure to DHA (Figure 2a), there was significant increase in Perilipin A mRNA expression $(p<0.01)$ in both subcutaneous and visceral cells, compared to the controls, and of leptin mRNA only

(a) DHA $\square$ Subcutaneous $\square$ Visceral

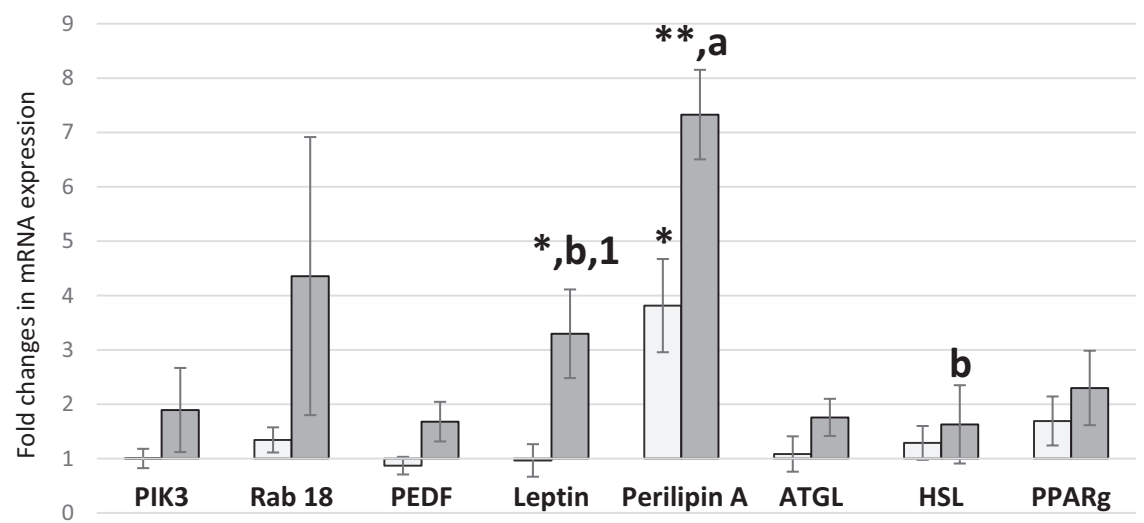

(b) EPA $\square$ Subcutaneous $\square$ Visceral

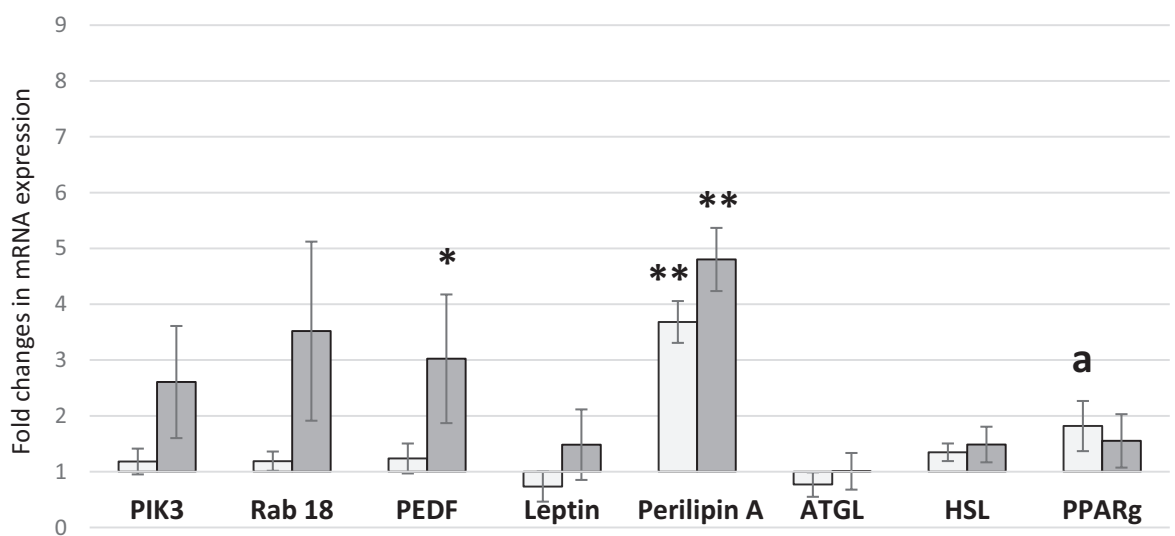

FIGURE 2 The data represent fold changes in mRNA expression for subcutaneous and visceral cells upon DHA (chart a) and EPA (chart b) treatments. With asterisks are marked the levels of significance for each tissue and treatment type compared to its relative control group as follow: ${ }^{*} p<0.05$ and ${ }^{* *} p<0.01$. The significances between DHA and EPA treatments in visceral cells are expressed as number $1(=p<0.05)$. The significant changes between subcutaneous and visceral cells in DHA/EPA, respectively, treated groups are shown with small letters a $(=p<0.05)$ and $\mathrm{b}(=p<0.01) .(n=6$, Error Bars $=$ SEM $)$ 
(a) SubcutaneousDHA

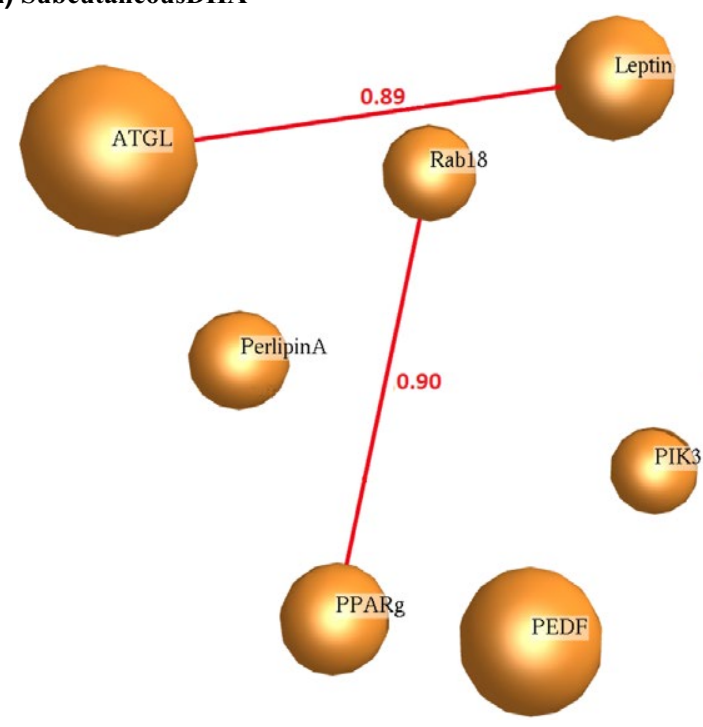

(c) Subcutaneous EPA

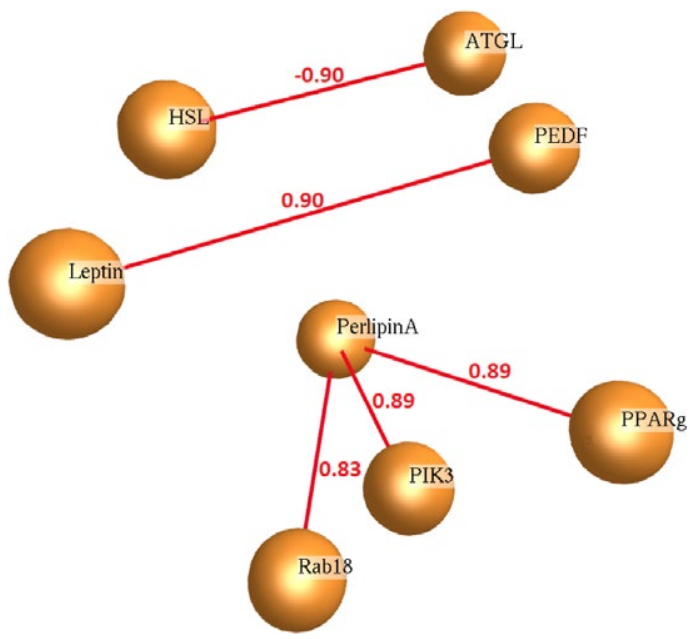

(b) Visceral DHA

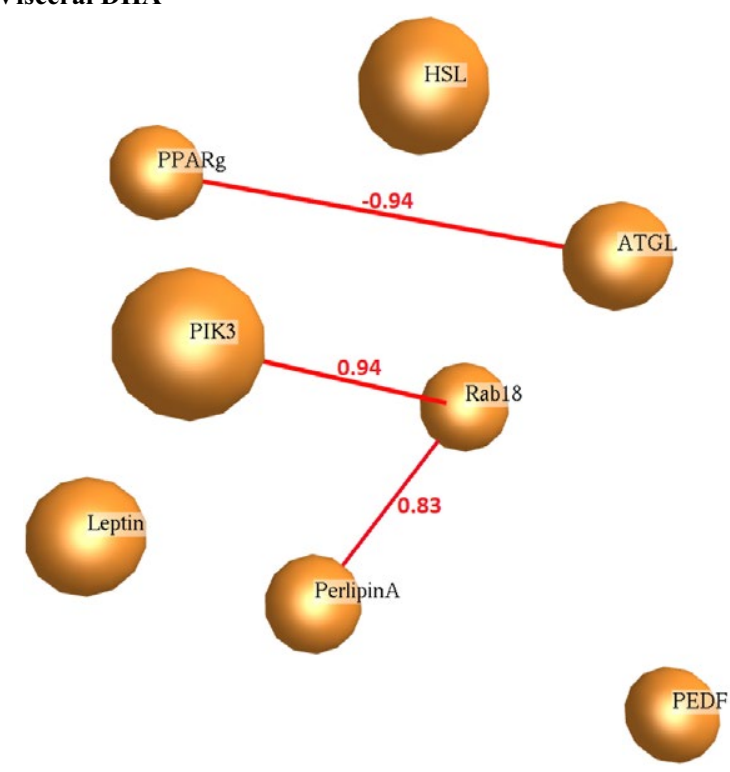

(d) Visceral EPA
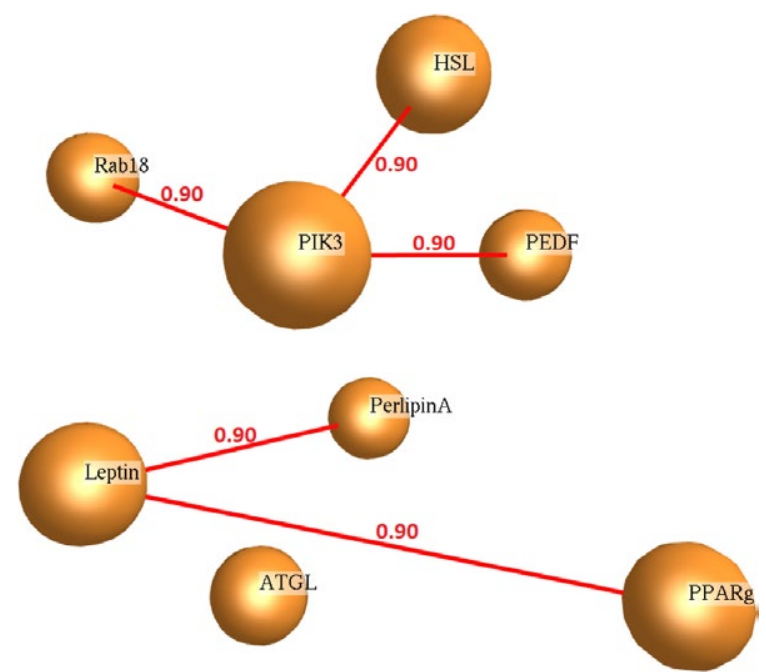

FIGURE 3 Correlation coefficient ( $r$ ) within mRNA expression of HSL, ATGL, PPAR $\gamma$, Perilipin A, Leptin, PEDF, Rab 18 and PI3K in subcutaneous and visceral ADSCs form rabbits (red lines indicate $r>0.80$ ), treated with DHA (a and b) and EPA (c and d) [Colour figure can be viewed at wileyonlinelibrary.com]

in visceral cells $(p<0.01)$. Similarly, exposure to EPA (Figure $2 \mathrm{~b})$ resulted in significant increase, compared with the controls, of Perilipin A mRNA expression $(p<0.01)$ in both subcutaneous and visceral cells too, while pigment epithelium-derived factor (PEDF) mRNA was enhanced only in visceral cells $(p<0.05)$.

Significant differences between subcutaneous and visceral DHA-treated cells were established for HSL $(p<0.01)$, leptin $(p<0.01)$ and Perilipin A $(p<0.05)$. When comparing EPAtreated subcutaneous and visceral cells, there was stronger PPAR $\gamma(p=0.05)$ expression in subcutaneous cells. In visceral cells, DHA had a stronger $(p<0.05)$ impact on leptin mRNA expression than EPA. Both n-3 PUFAs influenced Rab18 (Ras-related protein, small Rab GTPase) mRNA 3- to 4-fold in visceral cells insignificantly.
With regard to the ADSCs' origin and treatments, the data obtained reveal different correlation dependences (Figure 3). In the control group from subcutaneous cells, PPAR $\gamma$ correlates positively with Rab18 ( $r=0.83, p<0.05)$ and HSL $(r=0.83, p<0.05)$, while in visceral cells it correlates negatively with ATGL $(r=-0.89, p<0.05)$, which in turn is positively linked with PEDF ( $r=0.90, p<0.05)$.

Exposure to DHA maintains the significantly positive PPAR $\gamma$ Rab18 $(r=0.90, p<0.05)$ correlation and leads to ATGL-leptin $(r=0.89, p<0.05)$ interaction in subcutaneous cells (Figure 3a). In visceral cells, DHA (Figure $3 \mathrm{~b}$ ) treatment resulted in significant positive Rab18-PI3K (phosphatidylinositide 3-kinases) ( $r=0.94$, $p<0.05)$ and Rab18-Perilipin A $(r=0.83, p<0.05)$ correlations, while the PPAR $\gamma$-ATGL relationship was still negative $(r=-0.94$, $p<0.01$ ). 
When subcutaneous ADSCs were treated with EPA, (Figure 3d), significantly positive relationships of Perilipin A with PI3K ( $r=0.89$, $p<0.05)$, Rab $18(r=0.83, p<0.05)$ and PPAR $(r=0.89, p<0.05)$ were detected. Furthermore, while leptin-PEDF correlated positively ( $r=0.90, p<0.05)$, HSL-ATGL $(r=-0.90, p<0.05)$ were negatively related in the same group. Concerning the visceral cells (Figure $3 \mathrm{~d}$ ), EPA caused strong positive interplay of PI3K with Rab18 $(r=0.90$, $p<0.05)$, PEDF $(r=0.90, p<0.05)$ and HSL $(r=0.90, p<0.05)$. Correlations were also observed between leptin and Perilipin A $(r=0.90, p<0.05)$, and PPAR $\gamma(r=0.90, p<0.05)$.

\section{DISCUSSION}

In general, the obtained results in this study demonstrated that treatment of differentiated rabbit ADSCs for $48 \mathrm{hr}$ with n-3 PUFAs in vitro caused switching and re-directing of their transcriptional profile to expression of lipolysis-related genes. We established enhancement of mRNA expression of several cellular genes-Perilipin A, leptin, PEDF and Rab18 (even though statistically insignificant, regarded as Rab 18 was elevated almost fourfold), mainly in visceral cells. It has been established that more than $95 \%$ of TAG hydrolase activity in murine white adipose tissue (WAT) is due to both enzymes, ATGL and HSL (Schweiger et al., 2006). Besides, Perilipin A is assumed as one of the most abundant lipid droplet (LD)-associated proteins (Brasaemle, Subramanian, Garcia, Marcinkiewicz, \& Rothenberg, 2009). In the current study, it was the most up-regulated gene by both n-3 PUFAs and those findings differ from the results reported in the 3T3 model (Wójcik et al., 2014). We assume that the established changes in Perilipin mRNA could be due to species-specific response (mice vs. rabbits) to PUFAs exposure. Having in mind that in the resting period Perilipin A protects TAGs in LDs from cytosolic lipase breakdown, we suggest that the significant upregulation of Perilipin A mRNA expression is the cellular response upon increased necessity of TAG storage (Fujimoto, Ohsaki, Cheng, Suzuki, \& Shinohara, 2008). After $\beta$-adrenergic/glucagon stimulation and activation of adenylyl cyclase/cAMP/PKA (protein kinase A) pathway, Perilipin A phosphorylation is essential for HSL-dependent lipolysis (Sztalryd et al., 2003; Miyoshi et al., 2006). Due to PKA phosphorylation, Perilipin A releases CGI-58 (Comparative Gene Identification-58), which is bound to the LD membrane (Yamaguchi, Omatsu, Matsushita, \& Osumi, 2004) and in turn co-activates ATGL in the initial step of TAG breakdown (Lass et al., 2006; Lu, Yang, \& Liu, 2010). In this scenario, if we assume that the phosphorylation of Perilipin A is the central regulatory hub for lipolytic events in the fat cell (Duncan, Ahmadian, Jaworski, Sarkadi-Nagy, \& Sul, 2007; Choi et al., 2010), then we can suspect a possible positive interaction between ATGL, HSL and Perilipin A. We did not observe it in any of treated groups which could be explained by the lack of $\beta$-adrenergic or glucagon stimulation. It has been reported that neither ATGL- nor HSL-deficiency greatly influenced the lipase patterns in white adipose tissue. Enzyme activities of mouse tissues on acylglycerol substrates were analysed as well, showing that ATGL- and
HSL-deficiencies can be compensated at least in part by other enzymes (Morak et al., 2012).

Recently, PEDF has been defined as one of the most abundant adipokines, able to activate several signalling pathways, which in turn lead to insulin resistance (Borg et al., 2011). A few years ago, Sunderland et al. (2012) reported that plasma PEDF was elevated in overweight youth (Sunderland et al., 2012). In our study, PEDF mRNA was significantly up-regulated by EPA only in visceral, but not in subcutaneous cells (Figure 1b). The elevated PEDF could promote ubiquitin-proteasome-mediated protein degradation of ATGL and this might contribute to progressive obesity, insulin resistance and a subsequent negative correlation between PEDF and ATGL expression in obesity (Crowe et al., 2009; Dai et al., 2013). On the surface of it, the increased expression of PEDF obtained in EPAtreated visceral cells could be assumed as predisposition for development of such a disturbance in visceral type of obesity. The more profound exploration of the established changes reveals different meaning of PEDF implication under diabetic and hypoxia-induced angiogenesis conditions (He, Cheng, Benyajati, \& Ma, 2015). The authors have reviewed the PEDF's anti-angiogenic mechanisms and its therapeutic potential in proliferative diabetic retinopathy. In this sense, though related to insulin resistance, the elevation of PEDF might be a protective and/or compensatory mechanism against obesity-related angiogenesis even in adipose tissue itself. The finding could benefit the expansion of therapeutic use of PUFAs and EPA in particular.

Besides PEDF, leptin was also reported to have an autocrine manner of action in mice via binding to adipocyte leptin receptors (Frühbeck, Aguado, \& Martínez, 1997). The addition of artificially high doses of leptin in primary cultures of porcine adipocytes causes lipolysis, associated with an increase in AGTL (Li, Zheng, Liu, \& Yang, 2010). In bovine primary adipocytes, leptin regulates lipolysis via a STAT3-mediated increase in ATGL abundance (Koltes \& Spurlock, 2013). Our results confirm such positive relation only in subcutaneous DHA-treated cells, although the leptin and ATGL mRNA expression levels were not increased. However, in visceral cells we established that DHA significantly up-regulated leptin mRNA expression. The increased levels of leptin described in obesity are found to cause insulin resistance mainly by suppression of two processes leading to increase of insulin sensitivity, adiposity and lipotoxicity (Paz-Filho, Mastronardi, Wong, \& Licinio, 2012). Adiponectin, on opposite, is reduced in obesity and that reduction is associated with insulin resistance, dyslipidemia and atherosclerosis in humans (Yadav, Kataria, Saini, \& Yadav, 2013). Previously, we reported (Vachkova et al., 2017) that DHA up-regulated adiponectin mRNA in visceral cells, while EPA did not affect it. Together these data reveal that DHA might have stronger potential for improving insulin resistance in visceral obesity, than EPA.

Another component of the LD coat involved in insulin-mediated lipogenesis and in $\beta$-adrenergic/glucagon-induced lipolysis is Rab18 (Pulido et al., 2011). We observed an upregulation of Rab 18 gene expression and a strong, significantly positive correlation between Rab18 and PI3K in visceral DHA and EPA-treated cells. PI3K has been 
reported as one of the central players in insulin signalling pathways leading to metabolic effects (Taniguchi, Emanuelli, \& Kahn, 2006). Moreover, $\mathrm{PI} 3 \mathrm{~K}$ might also act downstream of the insulin receptor in regulation the lipid droplet trafficking (Choi et al., 2010), which is also affected by Rab18. There is evidence that Rab18 does not interact with LDs until they increase in size (Ozeki et al., 2005). Rab18 was identified to be closely associated with LDs that undergo lipolysis, which suggests a supportive role for ATGL (Soni et al., 2009). Analysing the PI3K mRNA associations in EPA-treated visceral cells, we observed a positive correlation between it with PEDF and HSL, similar to Rab 18. These links may represent an increased lipolytic activity in EPA-treated visceral cells. In control groups, PI3K correlated with PEDF positively in subcutaneous cells and negatively in visceral cells, whereas the treatments with PUFAs provoked the opposite effects. Therefore, the tissue-specific effects of PUFAs could be in part due to PEDF and PEDF, in turn, might be the link between subcutaneous and visceral crosstalk realized via PI3K.

A limitation of the study is the evaluation of mRNA expression without protein measurement, because not always up-regulated mRNA synthesis is followed by significantly increased protein production. Nevertheless, the obtained experimental data might bring a new light in understanding the molecular mechanism of PUFAs effects on ameliorating the obesity-induced metabolic syndrome and related diseases.

In conclusion, the results obtained in our study indicate that both DHA and EPA up-regulate in vitro the mRNA expression of lipolysisassociated genes, mainly in visceral rabbit ADSCs. Both PUFAs did not affect adenylyl cyclase/cAMP/PKA-dependent lipolysis, but EPA augmented PEDF and leptin mRNA expression, which in turn might influence basal lipolysis in rabbit visceral ADSCs. The variety of correlations among the mRNA levels of lipolytic-associated genes suggests the enormous compensatory properties of visceral fat cells. These findings reveal the specific gene expression profile mediating a lipolytic potential of 3-n PUFAs on ADSCs and their beneficial effect with respect to obesity treatment and MS prevention.

\section{ACKNOWLEDGEMENTS}

Funded by Project 4/13 within Trakia University-FVM; Bilateral STSM within COST Action TD1101-RGB- Net-Dr. Darko Bosnakovski and Dr. Ekaterina Vachkova; Scholarship within EEA programme in Department of Clinical Science, University of Bergen - Dr. Ekaterina Vachkova, Prof. Ivan Penchev; Central Scientific and Research Laboratory - Trakia University; Alexander Brown-student, FVM, Trakia University.

\section{CONFLICT OF INTEREST}

The authors declare that they have no conflict of interest. All procedures performed in studies, involving animals, were in accordance with the ethical standards of the institution or practice at which the studies were conducted.

\section{REFERENCES}

Aguilera, C. M., Ramirez-Tortosa, M. C., Mesa, M. D., Ramirez-Tortosa, C. L., \& Gil, A. (2002). Sunflower, virgin-olive and fish oils differentially affect the progression of aortic lesions in rabbits with experimental atherosclerosis. Atherosclerosis, 162, 335-344. https://doi. org/10.1016/S0021-9150(01),00737-7

Ahmadian, M., Wang, Y., \& Sul, H. S. (2010). Medicine in focus: Lipolysis in adipocytes. The International Journal of Biochemistry \& Cell Biology, 42, 555-559. https://doi.org/10.1016/j.biocel.2009.12.009

Arimura, N., Horiba, T., Imagawa, M., Shimizu, M., \& Sato, R. (2004). The peroxisome proliferator-activated receptor gamma regulates expression of the perilipin gene in adipocytes. The Journal of Biological Chemistry, 279, 10070-10076. https://doi.org/10.1074/jbc. M308522200

Borg, M. L., Andrews, Z. B., Duh, E. J., Zechner, R., Meikle, P. J., \& Watt, M. J. (2011). Pigment epithelium-derived factor regulates lipid metabolism via adipose triglyceride lipase. Diabetes, 60, 1458-1466. https://doi.org/10.2337/db10-0845

Bosnakovski, D., Mizuno, M., Kim, G., Takagi, S., Okumura, M., \& Fujinaga, T. (2005). Isolation and multilineage differentiation of bovine bone marrow mesenchymal stem cells. Cell Tissue Research, 319, 243-253. https://doi.org/10.1007/s00441-004-1012-5

Bosnakovski, D., Mizuno, M., Kim, G., Ishiguro, T., Okumura, M., Iwanaga, T., ... Fujinaga, T. (2004). Chondrogenic differentiation of bovine bone marrow mesenchymal stem cells in pellet cultural system. Experimental Hematology, 32, 502-509. https://doi.org/10.1016/j. exphem.2004.02.009

Brasaemle, D. L., Rubin, B., Harten, I. A., Gruia-Gray, J., Kimmel, A. R., \& Londos, C. (2000). Perilipin A increases triacylglycerol storage by decreasing the rate of triacylglycerol hydrolysis. Journal of Biological Chemistry, 275, 38486-38493. https://doi.org/10.1074/ jbc.M007322200

Brasaemle, D. L., Subramanian, V., Garcia, A., Marcinkiewicz, A., \& Rothenberg, A. (2009). Perilipin A and the control of triacylglycerol metabolism. Molecular and Cellular Biochemistry, 326, 15-21. https:// doi.org/10.1007/s11010-008-9998-8

Chambrier, C., Bastard, J. P., Rieusset, J., Chevillotte, E., BonnefontRousselot, D., Therond, P., ... Vidal, H. (2002). Eicosapentaenoic acid induces mRNA expression of peroxisome proliferator-activated receptor gamma. Obesity Research, 10, 518-525. https://doi. org/10.1038/oby. 2002.70

Chen, Y. J., Kuo, W. H., Chang, Y. T., Huang, C. W., Liu, H. Y., Cheng, Y. H., ... Ding, S. T. (2015). Docosahexaenoic acid inhibits white adipogenesis and enhances mitochondrial biogenesis through SIRT1 and Hh Signaling. FASEB Journal, 29, 995-1011.

Choe, S. S., Huh, J. Y., Hwang, I. J., Kim, J. I., \& Kim, J. B. (2016). Adipose tissue remodeling: its role in energy metabolism and metabolic disorders. Frontiers in Endocrinology, 7, 30. https://doi.org/10.3389/ fendo.2016.00030

Choi, S. M., Tucker, D. F., Gross, D. N., Easton, R. M., DiPilato, L. M., Dean, A. S., ... Birnbaum, M. J. (2010). Insulin regulates adipocyte lipolysis via an Akt-independent signaling pathway. Molecular and Cellular Biology, 30, 5009-5020. https://doi.org/10.1128/MCB.00797-10

Crowe, S., Wu, L. E., Economou, C., Turpin, S. M., Matzaris, M., Hoehn, K. L., ... Watt, M. J. (2009). Pigment epithelium-derived factor contributes to insulin resistance in obesity. Cell Metabolism, 10, 40-47. https://doi.org/10.1016/j.cmet.2009.06.001

Dai, Z., Qi, W., Li, C., Lu, J., Mao, Y., Yao, Y., ... Cai, W. (2013). Dual regulation of adipose triglyceride lipase by pigment epithelium-derived factor: a novel mechanistic insight into progressive obesity. Molecular and Cellular Endocrinology, 377, 123-134. https://doi.org/10.1016/j. mce.2013.07.001

Duncan, R. E., Ahmadian, M., Jaworski, K., Sarkadi-Nagy, E., \& Sul, H. S. (2007). Regulation of lipolysis in adipocytes. Annual Review of 
Nutrition, 27, 79-101. https://doi.org/10.1146/annurev.nutr.27. 061406.093734

Frühbeck, G., Aguado, M., \& Martínez, J. A. (1997). In vitro lipolytic effect of leptin on mouse adipocytes: evidence for a possible autocrine/paracrine role of leptin. Biochemical and Biophysical Research Communications, 240, 590-594. https://doi.org/10.1006/ bbrc.1997.7716

Fujimoto, T., Ohsaki, Y., Cheng, J., Suzuki, M., \& Shinohara, Y. (2008). Lipid droplets: a classic organelle with new outfits. Histochemistry and Cell Biology, 130, 263-279. https://doi.org/10.1007/s00418-008-0449-0

Georgiev, I. P., Georgieva, T. M., Ivanov, V., Dimitrova, S., Kanelov, I., Vlaykova, T., ... Roussenov, A. (2011). Effects of castration-induced visceral obesity and antioxidant treatment on lipid profile and insulin sensitivity in New Zealand white rabbits. Research in Veterinary Science, 90, 196-204. https://doi.org/10.1016/j.rvsc.2010.05.023

He, X., Cheng, R., Benyajati, S., \& Ma, J. X. (2015). PEDF and its roles in physiological and pathological conditions: implication in diabetic and hypoxia-induced angiogenic diseases. Clinical Science, 128(11), 805-823. https://doi.org/10.1042/CS20130463

Kershaw, E. E., \& Flier, J. S. (2004). Adipose tissue as an endocrine organ. The Journal of Clinical Endocrinology \& Metabolism, 89, 2548-2556. https://doi.org/10.1210/jc.2004-0395

Koltes, D., \& Spurlock, D. (2013). Leptin increases adipose triglyceride lipase in bovine primary adipocytes. The FASEB Journal, 27, 373-378.

Laclaustra, M., Corella, D., \& Ordovas, J. M. (2007). Metabolic syndrome pathophysiology: The role of adipose tissue. NutritionMetabolism and Cardiovascular Diseases, 17, 125-139. https://doi.org/10.1016/j. numecd.2006.10.005

Lass, A., Zimmermann, R., Haemmerle, G., Riederer, M., Schoiswohl, G., Schweiger, M., ... Zechner, R. (2006). Adipose triglyceride lipase-mediated lipolysis of cellular fat stores is activated by CGI-58 and defective in Chanarin-Dorfman Syndrome. Cell Metabolism, 3, 309-319. https://doi.org/10.1016/j.cmet.2006.03.005

Li, Y. C., Zheng, X. L., Liu, B. T., \& Yang, G. S. (2010). Regulation of ATGL expression mediated by leptin in vitro in porcine adipocyte lipolysis. Molecular and Cellular Biochemistry, 333, 121-128. https://doi. org/10.1007/s11010-009-0212-4

Lu, X., Yang, X., \& Liu, J. (2010). Differential control of ATGL-mediated lipid droplet degradation by CGI-58 and GOS2. Cell Cycle, 9, 27192725. https://doi.org/10.4161/cc.9.14.12181

Miyoshi, H., Souza, S. C., Zhang, H. H., Strissel, K. J., Christoffolete, M. A., Kovsan, J., ... Greenberg, A. S. (2006). Perilipin promotes hormonesensitive lipase-mediated adipocyte lipolysis via phosphorylation-dependent and -independent mechanisms. Journal of Biological Chemistry, 281, 15837-15844. https://doi.org/10.1074/ jbc.M601097200

Morak, M., Schmidinger, H., Riesenhuber, G., Rechberger, G. N., Kollroser, M., Haemmerle, G., ... Hermetter, A. (2012). Adipose triglyeride lipase (ATGL) and hormone-sensitive lipase (HSL) deficiencies affect expression of lipolytic activities in mouse adipose tissues. Molecular \& Cellular Proteomics, 11, 1777-1789. https://doi.org/10.1074/mcp. M111.015743

Ozeki, S., Cheng, J., Tauchi-Sato, K., Hatano, N., Taniguchi, H., \& Fujimoto, T. (2005). Rab18 localizes to lipid droplets and induces their close apposition to the endoplasmic reticulum-derived membrane. Journal of Cell Science, 118, 2601-2611. https://doi.org/10.1242/jcs.02401

Paz-Filho, G., Mastronardi, C., Wong, M. L., \& Licinio, J. (2012). Leptin therapy, insulin sensitivity, and glucose homeostasis. Indian Journal of Endocrinology and Metabolism, 16, 549-555. https://doi. org/10.4103/2230-8210.105571

Penchev, G., Yonkova, P., Ribarski, S., Kostov, D., Vachkova, E., Grigorova, N., ... Georgiev, I. (2017). Morphological study on periadventitial adipose tissue of the aortic arch in a rabbit model of obesity: Preliminary results. Bulgarian Journal of Veterinary Medicine (online first), https:// doi.org/10.15547/bjvm.1083
Pulido, M. R., Diaz-Ruiz, A., Jiménez-Gómez, Y., García-Navarro, S., Gracia-Navarro, F., Tinahones, F., ... Malagón, M. M. (2011). Rab18 dynamics in adipocytes in relation to lipogenesis. Lipolysis and obesity. PLoS ONE, 6, 22931. https://doi.org/10.1371/journal.pone.0022931

Schoonjans, K., Staels, B., \& Auwerx, J. (1996). The peroxisome proliferator activated receptors (PPARS) and their effects on lipid metabolism and adipocyte differentiation. Biochimica Et Biophysica Acta (BBA)-Lipids and Lipid Metabolism, 1302(2), 93-109. https://doi. org/10.1016/0005-2760(96)00066-5

Schweiger, M., Schreiber, R., Haemmerle, G., Lass, A., Fledelius, C., Jacobsen, P., ... Zimmermann, R. (2006). Adipose triglyceride lipase and hormone-sensitive lipase are the major enzymes in adipose tissue triacylglycerol catabolism. The Journal of Biological Chemistry, 281, 40236-40241. https://doi.org/10.1074/jbc.M608048200

Slavov, E., \& Dzhelebov, P. (2010). Basic endocrine products of adipose tissue - A review. Bulgarian Journal of Veterinary Medicine, 13, 199-210.

Soni, K. G., Mardones, G. A., Sougrat, R., Smirnova, E., Jackson, C. L., \& Bonifacino, J. S. (2009). Coatomer-dependent protein delivery to lipid droplets. Journal of Cell Science, 122, 1834-1841. https://doi. org $/ 10.1242 /$ jcs. 045849

Sunderland, K. L., Tryggestad, J. B., Wang, J. J., Teague, A. M., Pratt, L. V., Zhang, S. X., ... Short, K. R. (2012). Pigment epithelium-derived factor (PEDF) varies with body composition and insulin resistance in healthy young people. The Journal of Clinical Endocrinology \& Metabolism, 97, 2114-2118. https://doi.org/10.1210/jc.2012-1894

Sztalryd, C., Xu, G., Dorward, H., Tansey, J. T., Contreras, J. A., Kimmel, A. R., \& Londos, C. (2003). Perilipin A is essential for the translocation of hormone-sensitive lipase during lipolytic activation. The Journal of Cell Biology, 161, 1093-1103. https://doi.org/10.1083/ jcb.200210169

Taniguchi, C. M., Emanuelli, B., \& Kahn, C. R. (2006). Critical nodes in signalling pathways: Insights into insulin action. NatureReviews Molecular Cell Biology, 7, 85-96. https://doi.org/10.1038/nrm1837

Todorčević, M., \& Hodson, L. (2016). The effect of marine derived n-3 fatty acids on adipose tissue metabolism and function. Journal of Clinical Medicine, 5, 3. https://doi.org/10.3390/jcm5010003

Trayhurn, P., \& Beattie, J. H. (2001). Physiological role of adipose tissue: white adipose tissue as an endocrine and secretory organ. Proceedings of the Nutrition Society, 60, 329-339. https://doi. org/10.1079/PNS200194

Vachkova, E., Bosnakovski, D., Bjørndal, B., Yonkova, P., Grigorova, N., \& Ivanova, Z. H. (2017). EPA and DHA influenced differently the mRNA expression levels of some lipolysis-related factors in subcutaneous and visceral rabbit ADSCs in vitro. In Proceedings of the International Scientific Conference "Veterinary Medicine in Service of People", 6-7 October 2017, Stara Zagora, Bulgaria. Retrieved from http://uni-sz.bg/ truni6/wp-content/uploads/vmf/file/8\%20Vachkova.pdf

Vachkova, E., Bosnakovski, D., Yonkova, P., Grigorova, N., Ivanova, Z. h., Todorov, P., \& Georgiev, I. P. (2016). Adipogenic potential of stem cells derived from rabbit subcutaneous and visceral adipose tissue in vitro. In Vitro Cellular \& Developmental Biology - Animal, 52, 829-837. https://doi.org/10.1007/s11626-016-0048-7

Wójcik, C., Lohe, K., Kuang, C., Xiao, Y., Jouni, Z., \& Poels, E. (2014). Modulation of adipocyte differentiation by omega-3 polyunsaturated fatty acids involves the ubiquitin-proteasome system. Journal of Cellular and Molecular Medicine, 18, 590-599. https://doi. org/10.1111/jcmm.12194

Wozniak, S. E., Gee, L. L., Wachtel, M. S., \& Frezza, E. E. (2009). Adipose tissue: the new endocrine organ? A review article. Digestive Diseases and Sciences, 54, 1847-1856. https://doi.org/10.1007/ s10620-008-0585-3

Yadav, A., Kataria, M. A., Saini, V., \& Yadav, A. (2013). Role of leptin and adiponectin in insulin resistance. Clinica Chimica Acta, 417, 80-84. https://doi.org/10.1016/j.cca.2012.12.007 
Yamaguchi, T., Omatsu, N., Matsushita, S., \& Osumi, T. (2004). CGI-58 interacts with perilipin and is localized to lipid droplets. Possible involvement of CGI-58 mislocalization in Chanarin-Dorfman syndrome. Journal of Biological Chemistry, 279, 30490-30497. https:// doi.org/10.1074/jbc.M403920200

Yanni, A. E. (2004). The laboratory rabbit: an animal model of atherosclerosis research. Laboratory Animals, 38, 246-256. https://doi. org/10.1258/002367704323133628

Zimmermann, R., Strauss, J. G., Haemmerle, G., Schoiswohl, G., BirnerGruenberger, R., Riederer, M., ... Zechner, R. (2004). Fat mobilization in adipose tissue is promoted by adipose triglyceride lipase. Science, 306, 1383-1386. https://doi.org/10.1126/science.1100747
How to cite this article: Vackova E, Bosnakovski D, Bjørndal B, et al. n-3 polyunsaturated fatty acids provoke a specific transcriptional profile in rabbit adipose-derived stem cells in vitro. J Anim Physiol Anim Nutr. 2019;103:925-934. https://doi. org/10.1111/jpn.13075 